\title{
The Canadian clinician-scientist training program must be reinstated
}

\author{
David D.W. Twa, ${ }^{1,2}$ Jordan W. Squair, ${ }^{1,3}$ Michael A. Skinnider, ${ }^{1,4}$ and Jennifer X. ji1,2 \\ ${ }^{1} \mathrm{MD} / \mathrm{PhD}$ Training Program, Faculty of Medicine, University of British Columbia (UBC), Vancouver, British Columbia, Canada. ${ }^{2} \mathrm{BC}$ Cancer Agency, Vancouver, British Columbia, Canada. \\ ${ }^{3}$ International Collaboration on Repair Discoveries (ICORD), Vancouver, British Columbia, Canada. ${ }^{4}$ Centre for High-Throughput Biology, UBC, Vancouver, British Columbia, Canada.
}

\begin{abstract}
Clinical investigators within the Canadian and international communities were shocked when the Canadian Institutes of Health Research (CIHR) announced that their funding for the MD/PhD program would be terminated after the 2015-2016 academic year. The program has trained Canadian clinician-scientists for more than two decades. The cancellation of the program is at odds with the CIHR's mandate, which stresses the translation of new knowledge into improved health for Canadians, as well as with a series of internal reports that have recommended expanding the program. Although substantial evidence supports the analogous Medical Scientist Training Program in the United States, no parallel analysis of the MD/PhD program has been performed in Canada. Here, we highlight the long-term consequences of the program's cancellation in the context of increased emphasis on translational research. We argue that alternative funding sources cannot ensure continuous support for students in clinician-scientist training programs and that platform funding of the MD/PhD program is necessary to ensure leadership in translational research.
\end{abstract}

The clinician-scientist community was shocked in June when the Canadian Institutes of Health Research (CIHR) announced that its funding for the $\mathrm{MD} / \mathrm{PhD}$ program would be terminated. In a letter to $\mathrm{MD} / \mathrm{PhD}$ program directors at Canadian medical schools, the CIHR cited budgetary constraints as the primary motivation for the cancellation of the program, which, at $\$ 1.8$ million (all figures are in Canadian dollars), constitutes approximately $0.15 \%$ of the agency's 2015 budget. Despite several internal reports that have recommended expanding clinical and translational research programs, and contrary to the CIHR's own mandate, the CIHR has not yet outlined a new approach to clinician-scientist trainee program funding. Moreover, despite substantial evidence supporting American $\mathrm{MD} / \mathrm{PhD}$ programs, no parallel evaluation of the $\mathrm{MD} / \mathrm{PhD}$ program has been performed within Canada that would justify this funding decision (1). The cancellation of this program represents a blow to Canadian and international medical research.

\section{The long-term benefits have been undervalued}

The cancellation of the $\mathrm{MD} / \mathrm{PhD}$ program is at odds with the reports of several expert committees as well as with the CIHR's own 2003 mandate, which emphasizes excellence "in the creation of new knowledge and its translation into improved health for Canadians, more effective health services and products, and a strengthened Canadian health care system" (2). A 2011 international review panel report noted that the success of clinical research is an important component of improving patient outcomes but commented that, while Canada has "a strong track

Authorship note: David D.W. Twa, Jordan W. Squair, Michael A. Skinnider, and Jennifer X. Ji contributed equally to this work.

Conflict of interest: The authors have declared that no conflict of interest exists.

Reference information: J Clin Invest. 2015;125(12):4317-4319. doi:10.1172/JCI85194. record in clinical research," translational research is currently underfunded (3). This report expressed "particular concern about the support for clinician-scientists, many of whom have $50 \%$ time or less for research" and recommended the development of a national strategy to support clinical and translational research. Similarly, a 2013 report addressing the deficit of patient-oriented research in Canada specifically recommended expanding $\mathrm{MD} / \mathrm{PhD}$ funding in order to support more students (4). In the face of these comments and the recommendations by the CIHR's own expert committees, the decision to defund the $\mathrm{MD} / \mathrm{PhD}$ program is mystifying.

The CIHR's decision is particularly perplexing, given that no attempt has been made to gauge the utility of the program within Canada or the potential repercussions of its termination. In contrast, several analyses of the Medical Scientist Training Program in the United States have concluded that the program is integral to fulfilling the translational research mandate of the NIH. A 2014 report found that American $\mathrm{MD} / \mathrm{PhD}$ program graduates were more successful in RPG and R01 grant competitions than were MD applicants (5). Moreover, while only $1.5 \%$ of American MDs were engaged in research-related careers in recent years (6), 89\% of $\mathrm{MD} / \mathrm{PhD}$ graduates held positions at academic or research institutions, and over $90 \%$ reported that research was a significant professional activity (7). Although no similar studies of the Canadian program have been conducted, 11 of the 16 clinicianscientist salary awards granted by the CIHR within the past three years were awarded to researchers holding combined $\mathrm{MD} / \mathrm{PhD}$ degrees, an observation that attests to the importance of dualdegree holders in Canadian research. These data suggest that the CIHR's decision to defund the MD/PhD program will negatively impact patient care and health outcomes for Canadians.

Several recent CIHR reports have highlighted the value of translational research to the Canadian health care system, and 


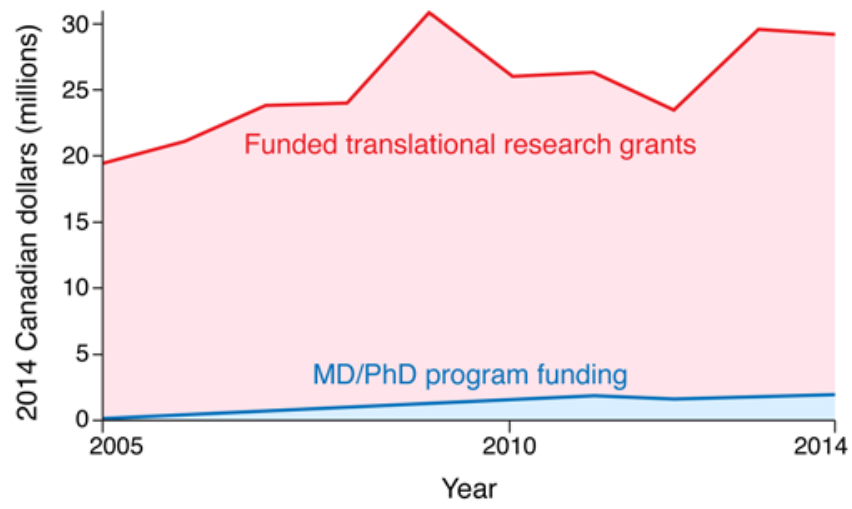

Figure 1. Combined value (2014 Canadian dollars in millions) of CIHRfunded grant proposals with the keyword "translational" and CIHR funding for MD/PhD training programs across Canada from 2005 to 2014. (Source: Canadian Research Information System).

CIHR funding competitions increasingly demand a translational component to new research proposals. In the past ten years, the Consumer Price Index-adjusted dollar value of CIHR-funded grant proposals with the keyword "translational" has increased dramatically and tracks with $\mathrm{MD} / \mathrm{PhD}$ program funding (Figure 1). However, the cancellation of the $\mathrm{MD} / \mathrm{PhD}$ program will reduce the number of individuals fluent in both patient care and basic science. These individuals have both the perspective to ask clinically relevant questions and the skill set to translate the answers into clinical care. A reduction in the number of medical professionals with protected research time is likely to further compromise patient-oriented research. The CIHR's emphasis on translational research is therefore fundamentally at odds with the termination of the MD/PhD program.

\section{The next generation needs to be sustained}

Physicians holding both $\mathrm{MD}$ and $\mathrm{PhD}$ degrees are uniquely trained to translate advances in basic science into improved health outcomes and patient care. In spite of the increasing need for experts capable of bridging the path from bench to bedside, few young researchers pursue careers as clinician-scientists. This is partly because the rigorous training required to pursue a career in translational medical research involves accepting significant lost or deferred income relative to that earned in traditional clinical or research careers. Up to 20 years may be required to complete $\mathrm{MD} / \mathrm{PhD}$ clinician-scientist training. The paucity of young clinician-scientists can also be attributed to the limited number of $\mathrm{MD} / \mathrm{PhD}$ positions that are funded nationwide. The recently terminated CIHR MD/PhD program grants supported approximately 20 incoming students each year over six-year periods. Consequently, competition for existing spots has historically been intense, and the number of applications submitted to the UBC program has increased by $250 \%$ since 2010, intensifying the already highly competitive process. The termination of CIHR support will further reduce the number of young clinician-scientists graduating from Canadian institutions.

The recently terminated CIHR MD/PhD program grants were the only funding sources designed to support students throughout the length of the combined degree program. Accordingly, Cana- dian MD/PhD students have few options to support their extensive training. The CIHR cited existing funding competitions for $\mathrm{MD} / \mathrm{PhD}$ students, including the Vanier Canada Graduate Scholarships and CIHR Doctoral Research Awards, as justification for the cancellation of the $\mathrm{MD} / \mathrm{PhD}$ program grants and noted that $\mathrm{MD} / \mathrm{PhD}$ students have historically performed very well in these competitions. However, the value of these awards has not tracked with inflation to offset the rising cost of tuition. Furthermore, these awards support individuals for only three years; in contrast, earning a combined $\mathrm{MD} / \mathrm{PhD}$ degree typically requires a seven- or eight-year program. As such, the CIHR MD/PhD program grants represented the only continuous funding source designed to support students throughout the entirety of their program. Moreover, no other national, provincial, or external funding competitions match the time commitment and stability of the six-year CIHR $\mathrm{MD} / \mathrm{PhD}$ program grants. The CIHR MD/PhD program grants therefore represented a commitment to the training of young clinician-scientists rather than a funding redundancy.

\section{Conclusions}

While the immediate effects of this decision may only affect current and prospective $\mathrm{MD} / \mathrm{PhD}$ students and program directors, the long-term consequences for the Canadian health care system are likely to be profound. The cancellation of the program reduces our ability to care for an aging population, particularly in the context of public health crises such as global antibiotic resistance. As medical practice becomes increasingly complex and we witness the advent of personalized medicine, there is a particular need for individuals capable of translating biotechnological advances into improved patient care. The future of translational research in Canada will be bleak without clinician-scientists capable of making these connections. We are grateful to those who have raised their concerns about this decision and ask the clinician-scientist community to continue to raise its voice. We urge the CIHR and the newly elected federal government to reconsider their decision and resume funding for the $\mathrm{MD} / \mathrm{PhD}$ program.

\section{About the authors}

David D.W. Twa is hosted by the Pathology and Laboratory Medicine Graduate Program at the UBC for his MD/PhD. As an affiliate of the BC Cancer Agency's Centre for Lymphoid Cancer, he is interested in modeling mutations identified in B cell malignancies and using high-throughput sequencing methods.

Jordan W. Squair is completing his $\mathrm{MD} / \mathrm{PhD}$ training at the ICORD under the Experimental Medicine Graduate Program at the UBC. His research is focused on understanding the cardiovascular consequences of spinal cord injury and developing novel strategies to restore proper autonomic control.

Michael A. Skinnider is completing his $\mathrm{MD} / \mathrm{PhD}$ in the Genome Sciences and Technology program at the UBC. His research aims to develop bioinformatic methods to interrogate the proteinprotein interactome.

Jennifer $\mathrm{X}$. Ji is an $\mathrm{MD} / \mathrm{PhD}$ student in the Department of Pathology and Laboratory Medicine at the UBC. Her research 
focuses on translating genomic and epigenomic landscape findings into disease management for patients affected by gynecologic cancers.

\section{Acknowledgments}

The authors are grateful to the director of the UBC MD/PhD Training Program, Lynn A. Raymond, and the associate director, Torsten O. Nielsen, for their encouragement, support, and input. D.D.W. Twa is supported by a CIHR Vanier Scholarship, a Kil- lam Scholarship, a UBC Four Year Fellowship, and the Canadian Hematology Society. J.W. Squair is supported by a CIHR Frederick Banting Charles Best Canada Graduate Scholarship and a UBC Four Year Fellowship. M.A. Skinnider is supported by a UBC Four Year Fellowship.

Address correspondence to: David Twa, (11-316) 675 West $10^{\text {th }}$ Avenue, Vancouver, BC Canada, V5Z 1L3. Phone: 604.675.8046; E-mail:dtwa@bccrc.ca.
1. Milewicz DM, Lorenz RG, Dermody TS, Brass LF. Rescuing the physician-scientist workforce: the time for action is now. JClin Invest. 2015;125(10):3742-3747.

2. Canadian Institutes of Health Research (CIHR). Our mandate. CIHR Web site. http://www. cihr-irsc.gc.ca/e/7263.html. Updated June 15, 2013. Accessed October 26, 2015.

3. CIHR. International Review Panel Report. CIHR Web site. http://www.cihr-irsc.gc.ca/e/43993.html.
Updated August 2, 2011. Accessed October 26, 2015.

4. CIHR. External Advisory Committee Report: Training and Career Development in PatientOriented Research. CIHR Web site. http://www. cihr-irsc.gc.ca/e/47693.html. Updated December 10, 2013. Accessed October 26, 2015.

5. NIH. Physician-Scientist Workforce (PSW) Report 2014 - Effects of Early Career NIH Programs on Physician-Scientists with a Medical Degree. NIH Web site. http://report.nih.gov/ workforce/psw/early_career_programs.aspx. Accessed October 26, 2015.

6. Garrison HH, Deschamps AM. NIH research funding and early career physician scientists: continuing challenges in the 21st century. FASEB J. 2013;28(3):1049-1058.

7. Schwartz P, Gaulton GN. Addressing the needs of basic and clinical research: analysis of graduates of the University of Pennsylvania MD-PhD program. JAMA. 1999;281(1):96-97. 